\title{
Vadose zone influences on aquifer parameter estimates of saturated-zone hydraulic theory
}

\author{
Jozsef Szilagyi* \\ Conservation and Survey Division, University of Nebraska, 113 Nebraska Hall, Lincoln, NE 68588 USA
}

Received 11 September 2002; revised 25 August 2003; accepted 12 September 2003

\begin{abstract}
Aquifer drainage was numerically simulated by a coupled, unsaturated-saturated flow equation. The effect of the vadose zone on aquifer parameter predictions of classical hydraulic theory was investigated. Saturated-zone hydraulic theory was shown to be fairly robust in estimating the saturated hydraulic conductivity but less so in estimating drainable porosity, mainly because of the much tighter possible range for the latter. Application of the coupled flow equation may explain discrepancies between predictions of classical saturated-zone theory and observations.

(C) 2003 Elsevier B.V. All rights reserved.
\end{abstract}

Keywords: Aquifer drainage; Aquifer parameter estimation; Vadose zone-saturated zone interactions

\section{Introduction}

The recession flow analysis first introduced by Brutsaert and Nieber (1977) is probably the only analytical tool for obtaining aquifer properties at the scale of the watershed (Szilagyi et al., 1998). Such work is of the utmost importance when so much effort in hydrology is devoted to scaling, aimed at bridging the potentially huge gap between the scale of sampling (generally in the order of centimeters for grain-size analysis and a few tens of meters for pumping tests) and the scale of interest. The latter may range from the scale of a single field to a watershed, or to regional or continental scales when one thinks of non-point source pollution of the groundwater, for example.

\footnotetext{
* Tel.: + 1-402-472-9667; fax: + 1-402-472-4608.

E-mail address: jszilagyil@unl.edu (J. Szilagyi).
}

Transient drainage of an aquifer underlain by a horizontal impervious layer is described (Whitham, 1974) by the Laplace equation in saturated flow theory:

$$
\frac{\partial^{2} H(x, y, t)}{\partial x^{2}}+\frac{\partial^{2} H(x, y, t)}{\partial y^{2}}=0
$$

where $H$ is the total hydraulic head, $x$ and $y$ are the horizontal and vertical coordinates and $t$ is time. Eq. (1) is subjected to the following boundary conditions:

$H(0, y, t)=h_{B}, t=0 ; H(0, y, t)=h_{0}, t>0$

$\partial H(x, 0, t) / \partial y=0 ; \partial H(B, y, t) / \partial x=0$

$H(x, y, t)=y=h(x, t)$ at the free surface

where $B$ is the breadth of the aquifer, $h_{\mathrm{B}}$ is the initial equilibrium water level in the stream, $h_{0}$ is the level to which the initial water level drops instantaneously 


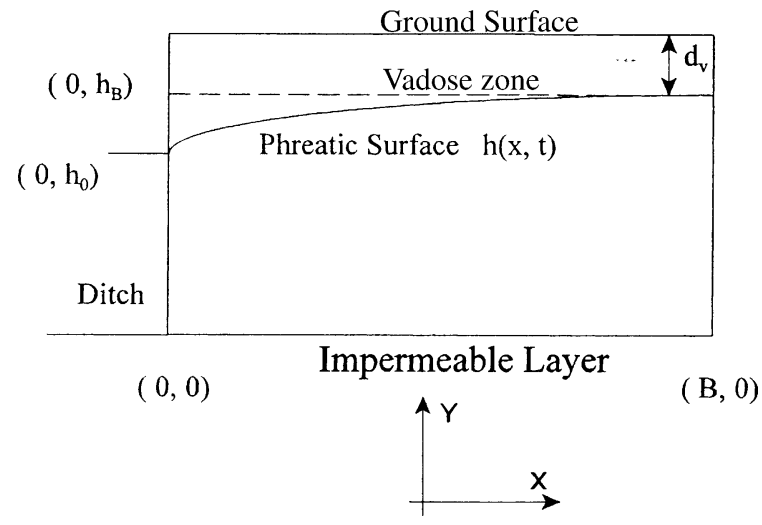

Fig. 1. Schematic representation of the stream-aquifer system.

(Fig. 1), and $h$ is the changing phreatic surface of the aquifer. The boundary condition on the phreatic surface is given by (Whitham, 1974; Van de Giesen et al., 1994)

$f \frac{\partial h}{\partial t}=k\left(\frac{\partial H}{\partial x} \frac{\partial h}{\partial x}-\frac{\partial H}{\partial y}\right)$

where $f$ is the drainable porosity or specific yield of the aquifer, and $k$ is the saturated hydraulic conductivity, both assumed to be constant. It is further assumed here that there is no contribution to the flow from the capillary fringe.

The Laplace Eq. (1) can be solved analytically (Van de Giesen et al., 1994) if (2b) is linearized, which implies that the changes in the phreatic surface elevation are small compared to the characteristic or average saturated thickness, $D\left(\approx h_{0}\right)$. Eq. ( $\left.2 \mathrm{~b}\right)$ then transforms to

$f \frac{\partial h}{\partial t}=-k \frac{\partial H}{\partial y}$

and so the discharge, $Q$, at $x=0$ is given (Van de Giesen et al., 1994) as

$$
\begin{aligned}
Q(t)= & \sum_{n=1,3, \ldots}^{\infty} k \frac{4\left(h_{\mathrm{B}}-h_{0}\right)}{n \pi} \tanh \left(\frac{n \pi h_{0}}{B}\right) \\
& \times \exp \left(-\frac{k}{f} \tanh \left(\frac{n \pi h_{0}}{B}\right) \frac{n \pi}{B} t\right) .
\end{aligned}
$$

Another way of solving the drainage problem involves the use of the Boussinesq equation in place of (1) (Van de Giesen et al., 1994)

$f \frac{\partial h}{\partial t}=k \frac{\partial^{2}\left(\frac{1}{2} h^{2}\right)}{\partial x^{2}}$

which assumes negligible pressure changes in the vertical direction (Dupuit's assumption) when $h_{B} \ll$ $B$. Parlange et al. (2001) presented a dimensionless approximate analytical solution of (4) for the case when $h_{0}$ is negligible compared to the average saturated thickness of the aquifer $(D)$

$$
\begin{aligned}
I^{*}= & \frac{5-\sqrt{7}}{2 \sqrt{\pi}} \sqrt{t^{*}}\left(1-\mathrm{e}^{-1 / t^{*}}\right)+\frac{5}{4} \operatorname{erfc}\left(\frac{1}{\sqrt{t^{*}}}\right) \\
& -\frac{1}{4}\left[\operatorname{erfc}\left(\frac{1}{\sqrt{t^{*}}}\right)\right]^{\sqrt{7}}
\end{aligned}
$$

Here $I^{*}$ is the dimensionless cumulative outflow volume, $I^{*}=\int_{0}^{t^{*}} Q^{*}(\tau) \mathrm{d} \tau$, and $Q^{*}=\left(B^{2} / k A D^{2}\right) Q$, where $A$ is the drainage area of the aquifer, $t^{*}$ is the dimensionless time, $t^{*}=D k t / f B^{2}$ and erfc is the complementary error function.

To see whether hydraulic properties of the vadose zone affect aquifer drainage and thus aquifer property estimates, analytical solutions (3) and (5) of classical groundwater-flow theory were compared to numerical solutions of the combined, unsaturated-saturated flow equation (Lam et al., 1987)

$\frac{\partial}{\partial x}\left(k(\psi) \frac{\partial H}{\partial x}\right)+\frac{\partial}{\partial y}\left(k(\psi) \frac{\partial H}{\partial y}\right)=m \gamma \frac{\partial H}{\partial t}$

where $k$ from now on also denotes the unsaturated hydraulic conductivity, a function of $\psi$, the suction/ pressure head; $m$ is the slope of the water-retention curve (volumetric water content, $\theta$, versus suction) at a given $\psi$ value, which becomes the coefficient of volume change in the saturated zone (Lam et al., 1987); $\gamma$ is the unit weight of water; and $H$, as before, is the total hydraulic head. In the numerical solution of (6), it is further assumed that the pore-air pressure remains atmospheric at all times. The integrations were carried out with the SVFlux 2D seepage modeling package (SoilVision Systems Ltd.) that uses a finite element approach. The model permits flux-exchange from the saturated zone across the entire saturated thickness at the stream-side of the aquifer, allowing for the development of a seepage 
Table 1

Parameter values in the Campbell model (after Clapp and Hornberger, 1978)

\begin{tabular}{lccccc}
\hline Texture & $\varphi$ & $k^{*}(\mathrm{~cm} / \mathrm{s})$ & $(\mathrm{m} / \mathrm{d})$ & $\left|\psi_{a e}\right|(\mathrm{cm})$ & $b$ \\
\hline Sand & 0.395 & $1.76 \times 10^{-2}$ & 15.21 & 12.1 & 4.05 \\
Loam & 0.451 & $6.95 \times 10^{-4}$ & 0.60 & 47.8 & 5.39 \\
Clay & 0.482 & $1.28 \times 10^{-4}$ & 0.11 & 40.5 & 11.4 \\
\hline
\end{tabular}

face. At early times of the drawdown, such a seepage zone is clearly discernible in Fig. 3a.

\section{Analysis and results}

In the numerical experiments, three basic aquifer textures were used: sand, loam, and clay. The waterretention, $\psi-\theta$, and the $k-\theta$ curves for the different texture types were estimated using the power law equations of Campbell (1974) for simplicity

$$
|\psi(\theta)|=\left|\psi_{\mathrm{ae}}\right|\left(\frac{\varphi}{\theta}\right)^{b}
$$

$k(\theta)=k^{*}\left(\frac{\theta}{\varphi}\right)^{c}$

where $\psi_{\mathrm{ae}}$ is the air entry suction, $\varphi$ is the total porosity, $b$ is the so-called pore-size distribution index, $c(\approx 2 b+3)$ is the so-called pore-disconnectedness index, and $k^{*}$ is the assumed saturated hydraulic conductivity of the given aquifer texture. The values of the parameters for the three types of texture used in the numerical model are listed in Table 1. Fig. 2 displays the resulting $\psi-\theta$, and $k-\theta$ curves. The fourth texture type included in Fig. 2 has mild and linear changes in hydraulic properties; thus it was named 'linear aquifertexture'. The hydraulic property curves were extended for suctions smaller than the air-entry value by near-constant segments. The numerical model takes $k^{*}$ as the $k$ value belonging to the smallest suction defined, while it extends the $\psi-\theta$ curve into the saturated zone by a linear extrapolation prohibiting vanishing slopes.

The first set of experiments involved an aquifer with $B=6 \mathrm{~m}, h_{\mathrm{B}}=3 \mathrm{~m}, h_{0}=2.8 \mathrm{~m}$, with total aquifer depth (vadose plus phreatic zones together)
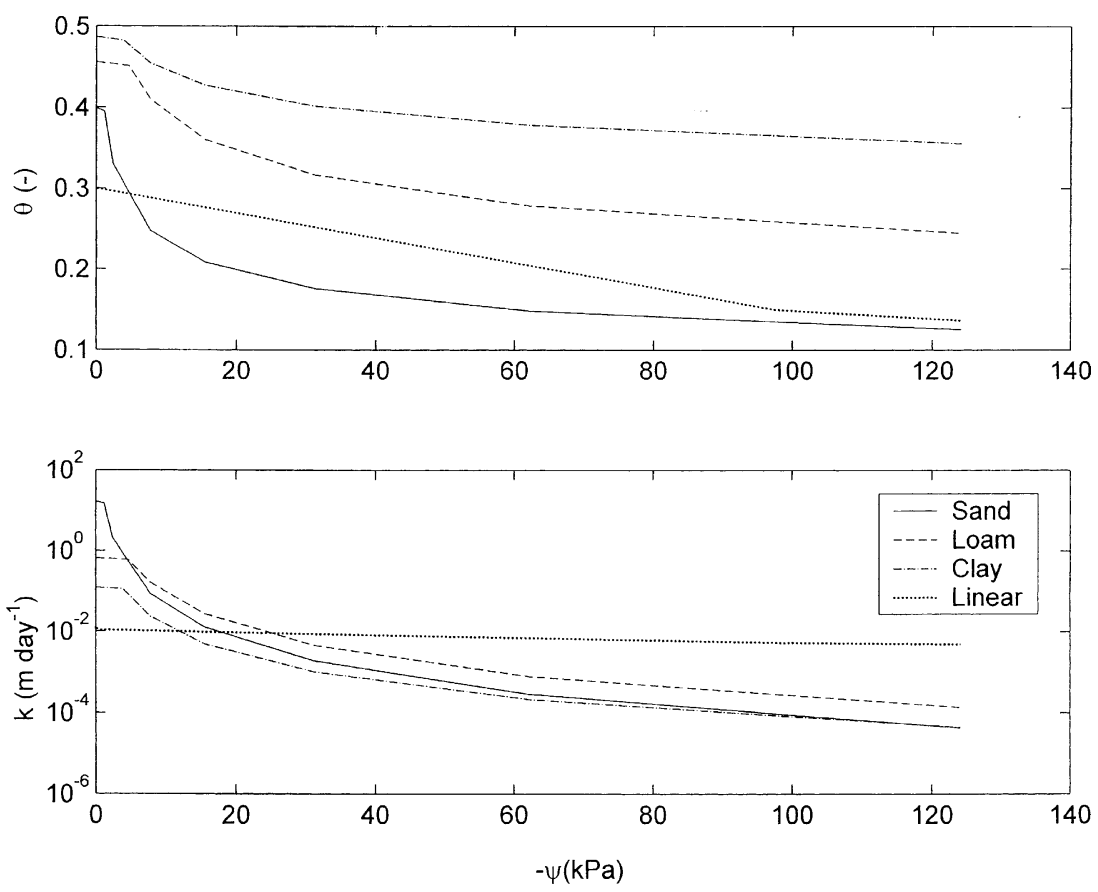

Fig. 2. Hydraulic properties of the aquifer textures used in the numerical model. 

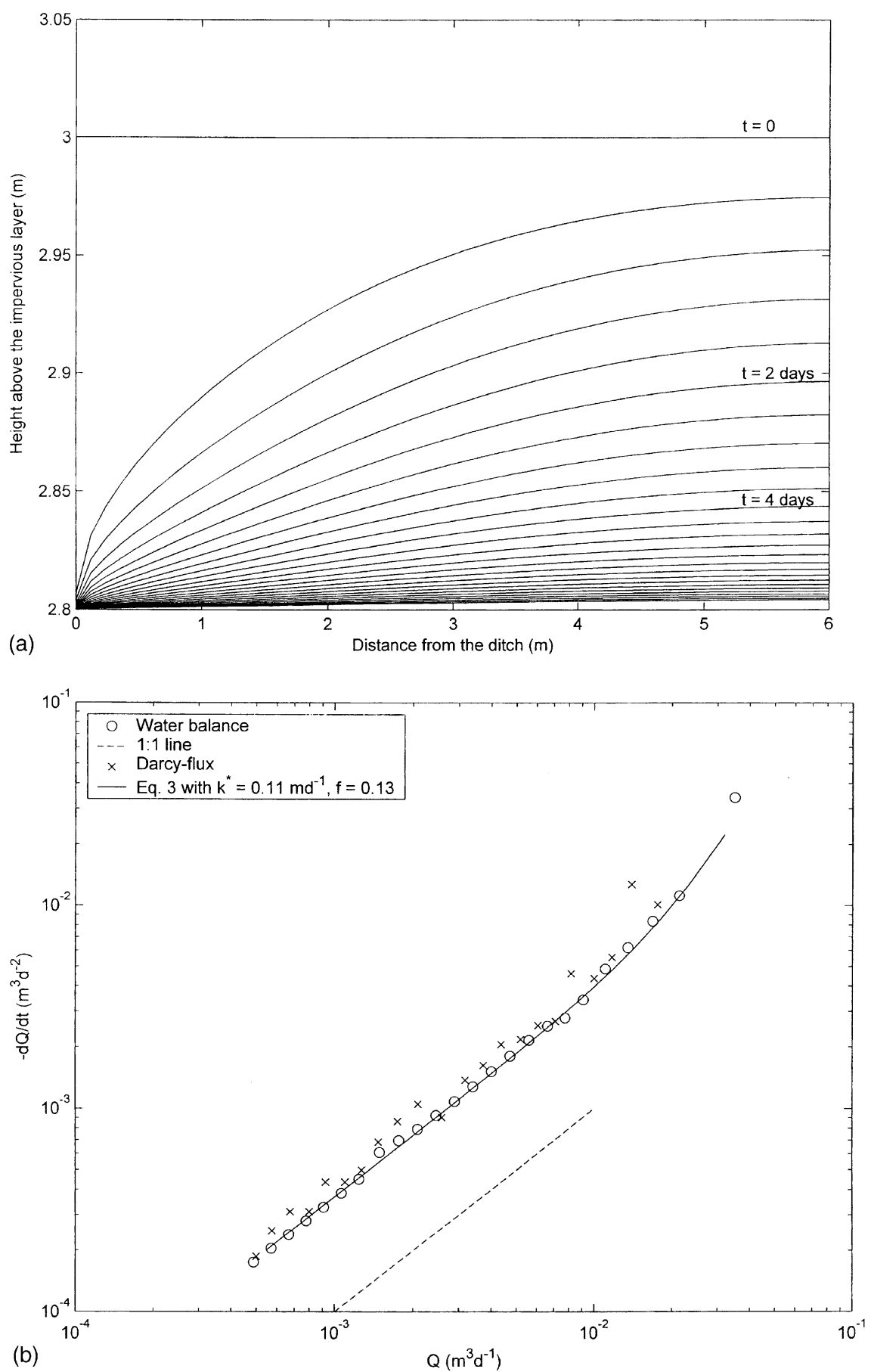

Fig. 3. (a) 10 days of drawdown of a clay aquifer with $B=6 \mathrm{~m}, h_{0}=2.8 \mathrm{~m}, h_{\mathrm{B}}=3 \mathrm{~m}$, and $d_{\mathrm{v}}=1.1 \mathrm{~m}$; (b) $Q$ versus $-\mathrm{d} Q / \mathrm{d} t$ values of the numerical and analytical solutions for a unit length of the aquifer. 
Table 2

Eq. (3)-fitted aquifer parameters for different textures and vadose-zone thicknesses

\begin{tabular}{|c|c|c|c|c|}
\hline \multirow{7}{*}{$\begin{array}{l}\text { Vadose-zone thickness }(\mathrm{m}) \\
\text { Sand }\left(k^{*}=15.21 \mathrm{~m} / \mathrm{d}\right) \\
f=\theta(\psi=0 \mathrm{kPa})-\theta(\psi=-124 \mathrm{kPa})=0.274 \\
\text { Loam }\left(k^{*}=0.60 \mathrm{~m} / \mathrm{d}\right) \\
f=\theta(\psi=0 \mathrm{kPa})-\theta(\psi=-124 \mathrm{kPa})=0.21 \\
\text { Clay }\left(k^{*}=0.11 \mathrm{~m} / \mathrm{d}\right) \\
f=\theta(\psi=0 \mathrm{kPa})-\theta(\psi=-124 \mathrm{kPa})=0.131\end{array}$} & \multicolumn{4}{|c|}{$B=6 m ; h_{0}=2.8 m ; h_{\mathrm{B}}=3 m$} \\
\hline & 0.1 & 1.1 & 3.1 & 13.1 \\
\hline & $k_{\mathrm{fit}}=15 \mathrm{~m} / \mathrm{d}$ & $k_{\mathrm{fit}}=13 \mathrm{~m} / \mathrm{d}$ & $k_{\text {fit }}=12 \mathrm{~m} / \mathrm{d}$ & $k_{\mathrm{fit}}=14 \mathrm{~m} / \mathrm{d}$ \\
\hline & $f_{\text {fit }}=0.17$ & $f_{\text {fit }}=0.40$ & $f_{\text {fit }}=0.41$ & $f_{\text {fit }}=0.43$ \\
\hline & $k_{\mathrm{fit}}=1.20 \mathrm{~m} / \mathrm{d}$ & $k_{\mathrm{fit}}=0.55 \mathrm{~m} / \mathrm{d}$, & $k_{\mathrm{fit}}=0.40 \mathrm{~m} / \mathrm{d}$ & $k_{\mathrm{fit}}=0.45 \mathrm{~m} / \mathrm{d}$, \\
\hline & $f_{\text {fit }}=0.04$ & $f_{\text {fit }}=0.20$ & $f_{\text {fit }}=0.38$ & $f_{\text {fit }}=0.42$ \\
\hline & $\begin{array}{l}k_{\mathrm{fit}}=0.21 \mathrm{~m} / \mathrm{d} \\
f_{\text {fit }}=0.03\end{array}$ & $\begin{array}{l}k_{\text {fit }}=0.13 \mathrm{~m} / \mathrm{d}, \\
f_{\text {fit }}=0.15\end{array}$ & $\begin{array}{l}k_{\text {fit }}=0.10 \mathrm{~m} / \mathrm{d} \\
f_{\text {fit }}=0.24\end{array}$ & $\begin{array}{l}k_{\text {fit }}=0.09 \mathrm{~m} / \mathrm{d}, \\
f_{\text {fit }}=0.22\end{array}$ \\
\hline
\end{tabular}

values of 3.1, 4.1, 6.1 and $16.1 \mathrm{~m}$ for all three textures. The outflow values, $Q(t)$, were calculated by two methods: the first is a water balance approach, where the outflow equals the change of the total water content of the aquifer (including saturated and unsaturated zones) divided by the time-increment, while the second is an integration of Darcy fluxes along the total length of the stream/atmosphereaquifer interface (saturated and unsaturated).

Fig. 3 shows a typical drawdown for a clay aquifer $4.1 \mathrm{~m}$ deep. The analytical solution, (3), was obtained by using the $f$ and $k^{*}$ values defined in Tables 1 and 2 .
Because in the water-balance approach the discharge values were calculated as the change in total water content of the coupled systems (vadose and phreatic) between subsequent time increments, it yields smoother values than the other method based on instantaneous Darcy-fluxes integrated over the stream-aquifer and aquifer-atmosphere interfaces (due to the seepage face). Subsequent aquifer parameter estimates were obtained by an automated curve-fitting procedure in a least-square sense of the logarithms using the water-balance values only. Together with the exact values of the so-derived

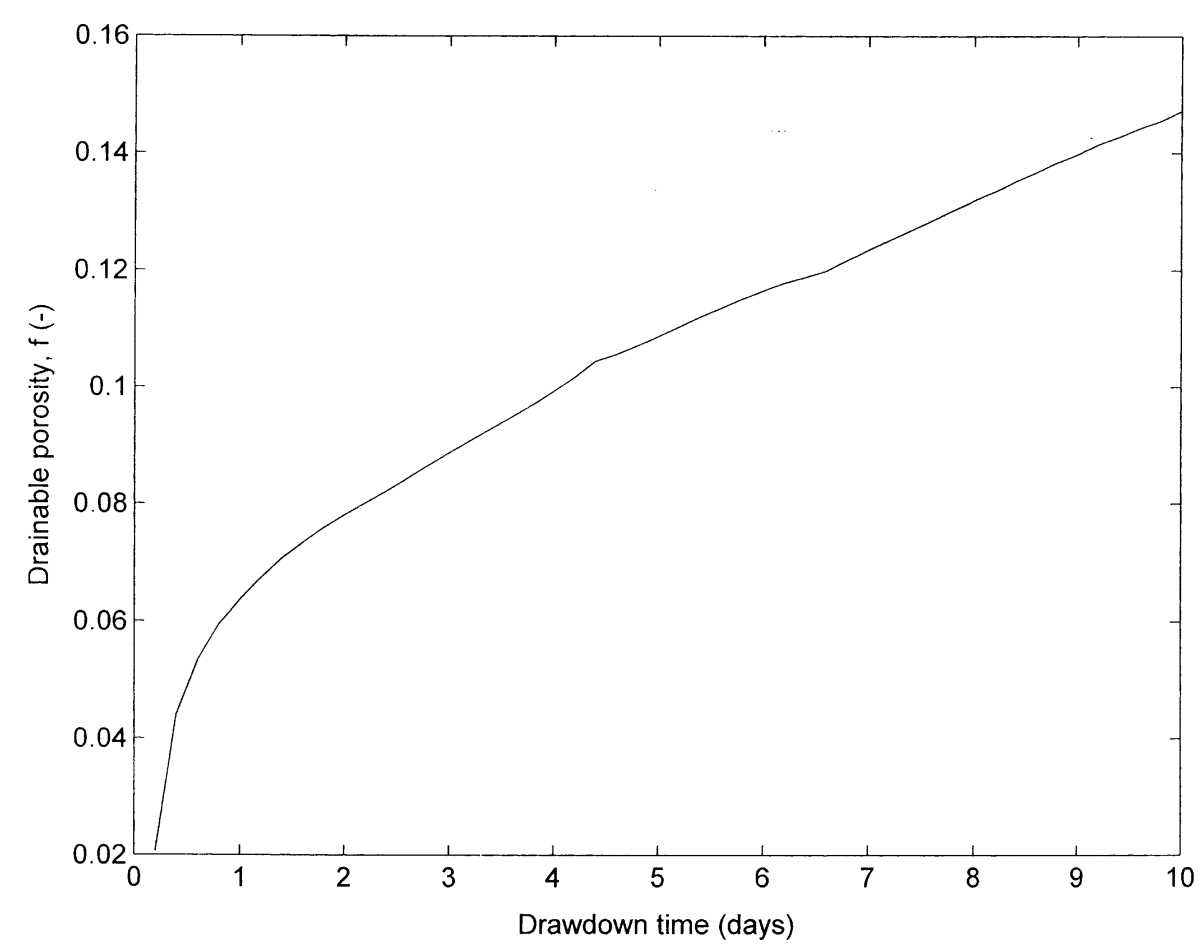

Fig. 4. Changes in drainable porosity during drainage of the clay aquifer with a vadose zone $3.1 \mathrm{~m}$ thick. 
aquifer parameter estimates, the change in aquifer response, and thereby in estimated aquifer parameter values, to modifications in the hydraulic properties of the vadose zone were of interest in this study. The changes, in addition to switching between aquifer textures, were induced by varying the total depth of the aquifer while leaving the saturated thickness intact. The numerical model calculates the initial soilmoisture distribution in the vadose zone under hydrostatic conditions. Varying the thickness of the vadose zone thus means that the drawdowns start with different ranges of the initial soil-moisture and hydraulic conductivity values.

Results of the simulations are summarized in Table 2. It can be seen that when changes in the $\psi-$ $\theta$ and $k-\theta$ curves are already small (i.e. $\psi \lesssim-60$ or $d_{\mathrm{v}} \gtrsim 6 \mathrm{~m}$, see Fig. 2) with decreasing $\psi$, additional increase in the vadose zone thickness $\left(d_{\mathrm{v}}\right)$ does not affect the estimated aquifer property values much further. While the saturated conductivity estimates fluctuate around the prescribed values, $k^{*}$, and tend to decrease with increasing vadose zone thickness, the estimated drainable porosity values become systematically larger than the physically interpretable maximum value. The former can be explained by the decreasing conductivity of the vadose zone as it dries out, increasing the resistance of the unsaturated/ saturated system to releasing surplus water. The physical explanation of the latter, however, may not be all that obvious. It should be noted here that saturated hydraulic theory ( $2 \mathrm{~b}$ and 4 ) assumes that the drainable porosity is a constant value during drawdown. As the hydraulic conductivity of the unsaturated/saturated system may decrease during drawdown, so may the drainable porosity increase as discussed in Bear (1988) and is demonstrated in Fig. 4. Since the vadose zone delivers extra water to the drainage, classical hydraulic theory sees it as a virtual increase in the drainable porosity. Consequently the thicker the vadose zone the more significant this unsaturated water contribution and so larger the estimated specific yield value, up to a critical

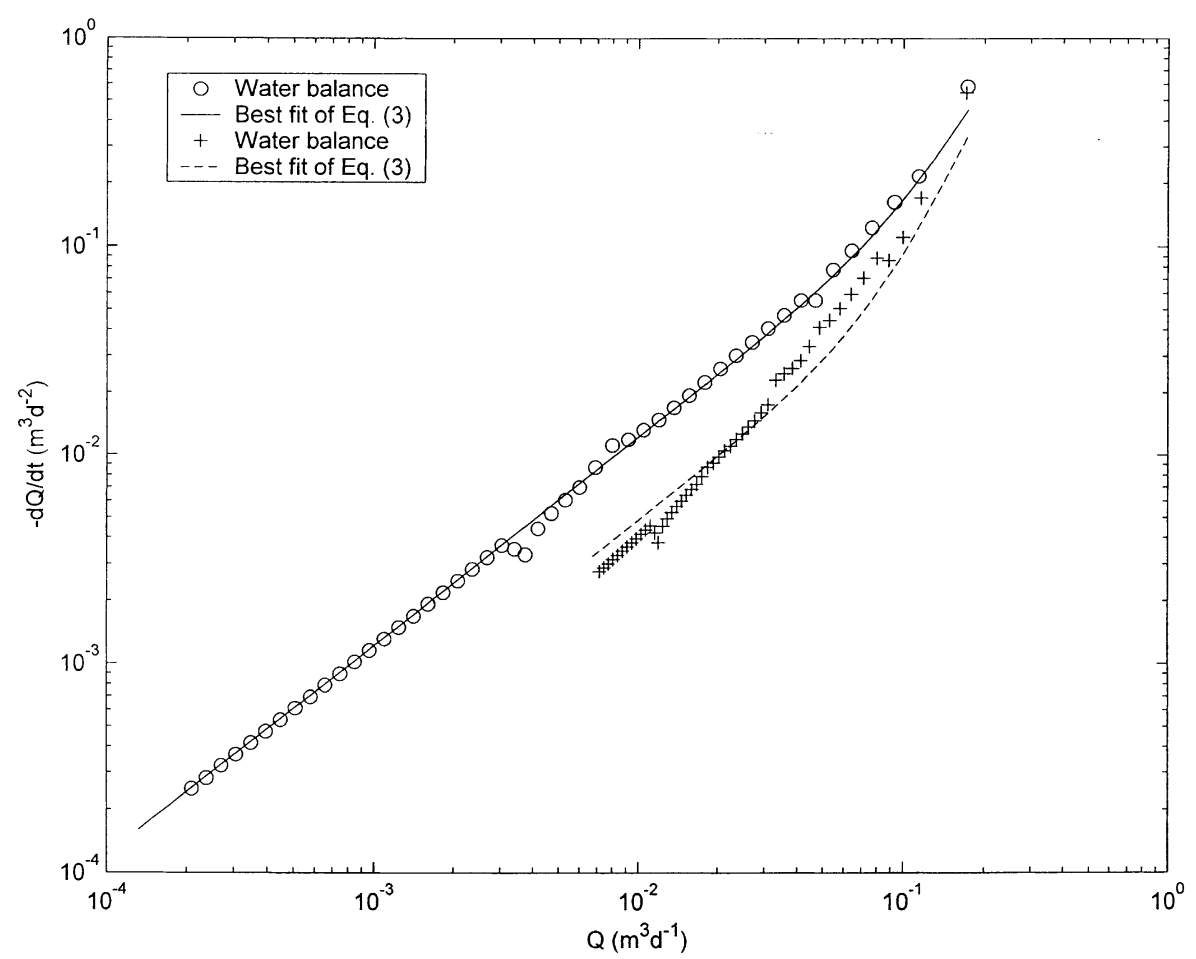

Fig. 5. $Q$ versus $-\mathrm{d} Q / \mathrm{d} t$ values of the numerical and best-fit analytical solutions of five days of loam aquifer drainage of unit length with two different vadose-zone thicknesses, 1.1 (upper group of data points) and $3.1 \mathrm{~m}$. 
thickness above which further increase in $d_{\mathrm{v}}$ does not mean additional source of water to drainage. Fig. 5 illustrates that the reported changes in estimated aquifer values are not the result of possible poor data fitting.

In the second set of experiments, $h_{0}$ was set to be zero $\left(h_{B}\right.$ remained $\left.3 \mathrm{~m}\right)$, and the aquifer breadth, $B$, was increased to $120 \mathrm{~m}$. This satisfies the requirements of (5), which predicts a slope of 3 in early period of drawdown, transforming into a slope of 1.5 as time progresses on the double logarithmic graph of the $Q$ versus $-\mathrm{d} Q / \mathrm{d} t$ values. Note that (3) predicts a slope of unity at large times of drawdown (Fig. 3b).

In Fig. 6 a slope of 1.5 indeed is observable, where the $Q$ versus $-\mathrm{d} Q / \mathrm{d} t$ values of a draining clay aquifer with a vadose-zone thickness $\left(d_{\mathrm{v}}\right)$ of $13.1 \mathrm{~m}$ are shown. The original slope of 3 is partly missing for the water-balance calculated values because of the relatively large time increment $(\mathrm{d} t=400$ days) used for reducing data scatter. Numerical calculations with this setting become cumbersome because of the significantly increased time-requirement of the computations. For this reason no attempt was made to repeat the aquifer parameter estimation exercise demonstrated above. It could be carried out in a similar vein as before but with the application of (5), as is explained in Parlange et al. (2001) and demonstrated in Fig. 6 where the best-fit of (5) yields $k_{\text {fit }}=0.40 \mathrm{~m} \mathrm{~d}^{-1}$ and $f_{\text {fit }}=0.22$. This latter estimate is identical to the previous clay aquifer case of identical vadose zone thickness. Here we mention an interesting observation. If the clay is replaced by the so-called linear aquifer texture (Fig. 2), where hydraulic properties change smoothly, then the original slope of 3 at early times of the drawdown turns into a slope very close to unity (Fig. 7), leaving out the 1.5 slope-segment hypothesized by Parlange et al. (2001). A reduced rate of change in drawdown (i.e. a slope of unity instead of 1.5) now is caused by an increased level of water flux from the vadose zone to the saturated zone throughout the entire length of the drawdown due to a near-constant hydraulic

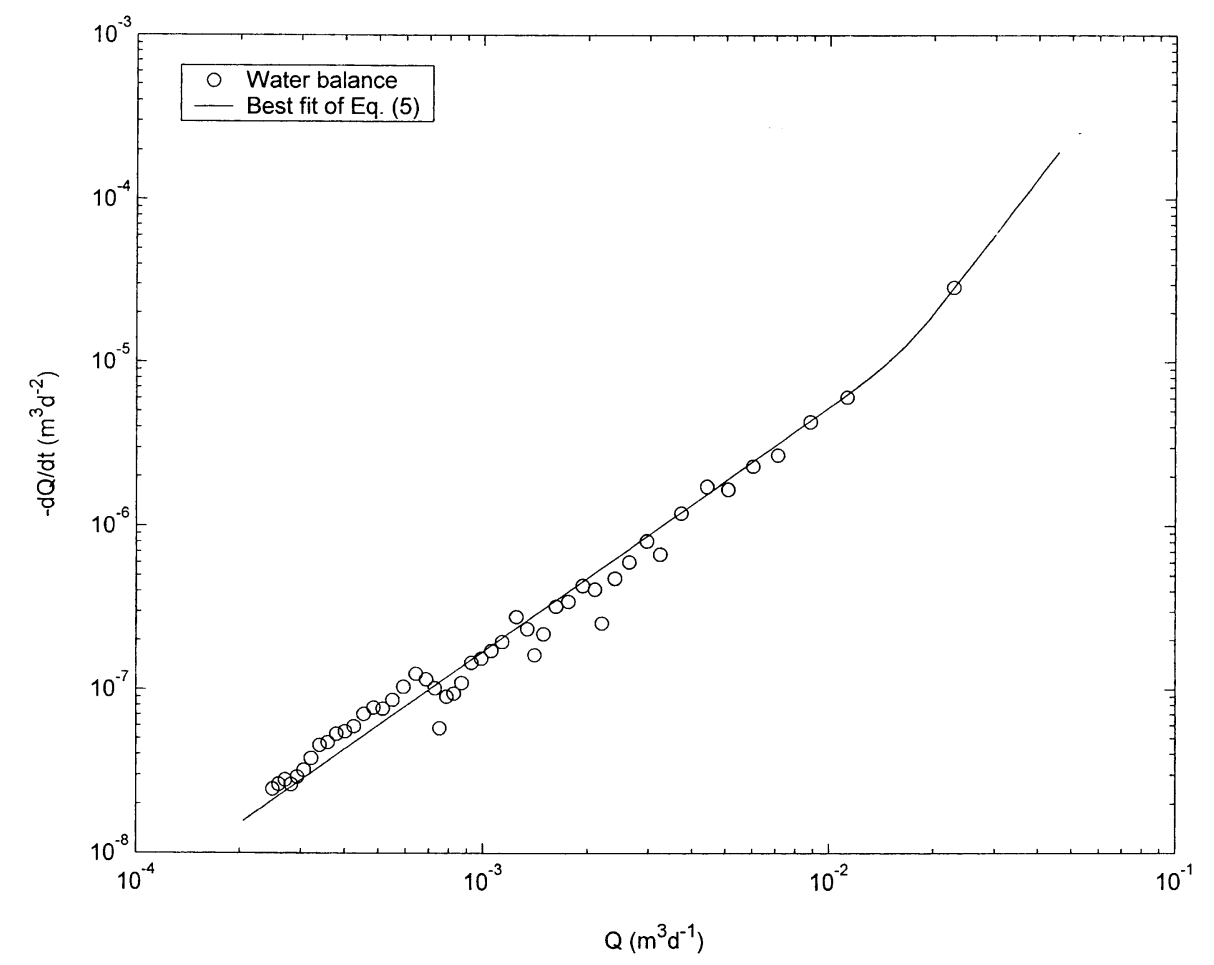

Fig. 6. $Q$ versus $-\mathrm{d} Q / \mathrm{d} t$ values of drainage $\left(h_{0}=0\right)$ of a clay aquifer with unit length, satisfying the Dupuit-condition. 


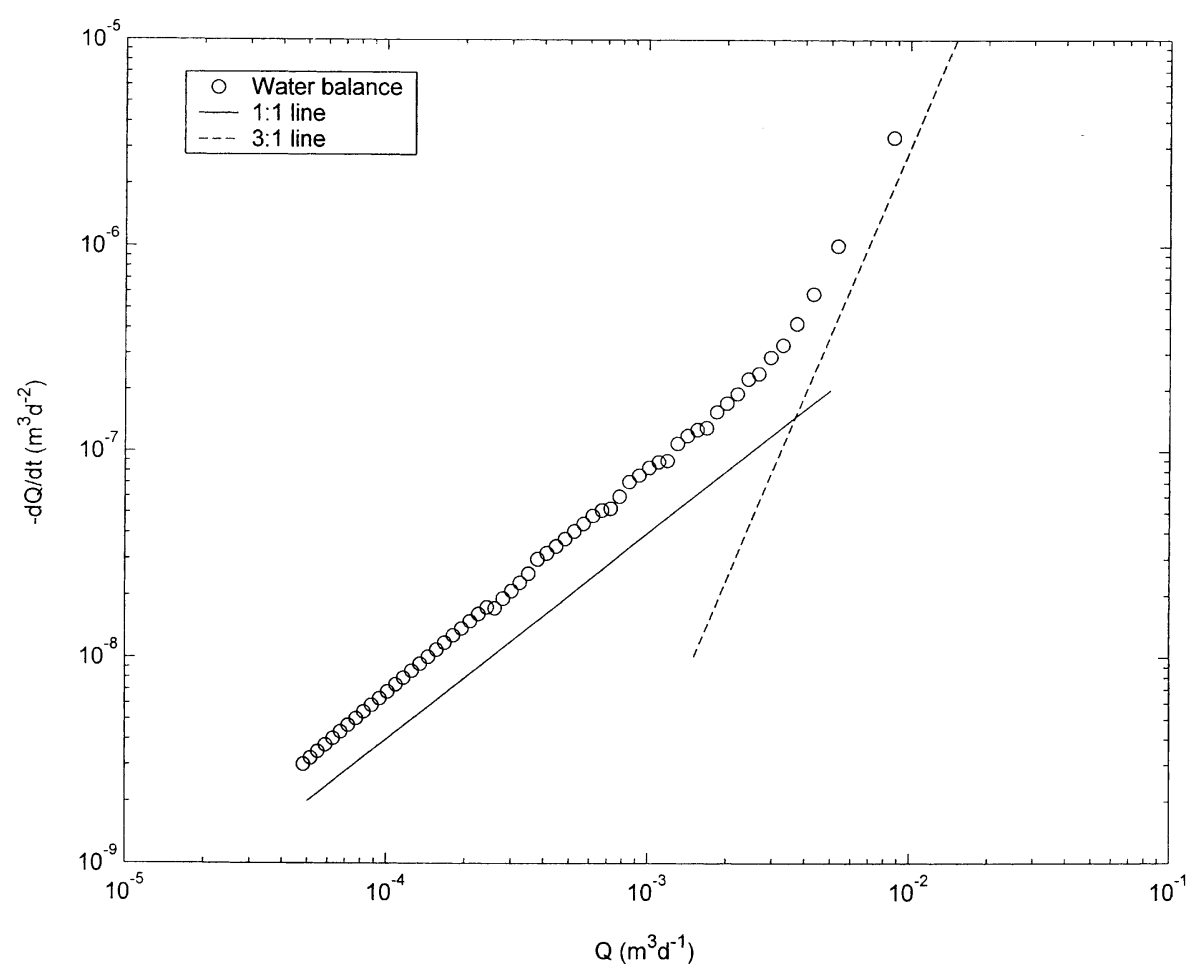

Fig. 7. $Q$ versus $-\mathrm{d} Q / \mathrm{d} t$ values of drainage $\left(h_{0}=0\right)$ of an aquifer of unit length with linearly changing vadose-zone properties, satisfying the Dupuit-condition.

conductivity value. Thereby a slope of unity with this setting cannot be explained by classical saturatedzone hydraulic theory. This example further underlines the potential importance of the vadose zone to groundwater drainage.

In conclusion, it should be emphasized that existing analytical approaches (Brutsaert and Nieber, 1977; Van de Giesen et al, 1994; Parlange et al., 2001) to aquifer parameter estimation are considered an indispensable tool for characterizing the subsurface at the watershed scale. The numerical data presented in this study do not invalidate the practical predictive power of these approaches (Szilagyi et al., 1998). While a discernible effect of the vadose zone on aquifer drainage and aquifer parameter estimation was demonstrated through simplified numerical experiments, the extension of the approach to a more realistic environment with spatially varying vadoseand saturated-zone hydraulic properties is yet to be accomplished. However, based on the above numerical experiments, classical hydraulic theory is expected to yield good field estimates of the saturated hydraulic conductivity, taking into account the wide range of possible values (spanning about ten magnitudes). The theory seems somewhat weaker in predicting drainable porosity values considering that the possible range for sedimentary materials is about one magnitude or less; hence, a $100 \%$ error in the estimate is already significant. In such cases, a combined unsaturated/saturated-system approach may become a useful tool in explaining possible deviations from theoretical predictions, as was illustrated in this study.

\section{Acknowledgements}

The author would like to thank Jean-Yves Parlange and the two anonymous reviewers for their valuable comments on an earlier version of the manuscript. 
The editorial comments of Charles Flowerday are also greatly appreciated.

\section{References}

Bear, J., 1988. Dynamics of Fluids in Porous Media, Dover. Brutsaert, W., Nieber, J.L., 1977. Regionalized drought flow hydrographs from a mature glaciated plateau. Water Resour. Res. 13, 637-643.

Campbell, G.S., 1974. A simple method for determining unsaturated conductivity from moisture retention data. Soil Sci. 117, 311-314.

Clapp, R.B., Hornberger, G.M., 1978. Empirical equations for some soil hydraulic properties. Water Resour. Res. 14, 601-604.
Lam, L., Fredlund, D.G., Barbour, S.L., 1987. Transient seepage model for saturated-unsaturated soil systems: a geotechnical engineering approach. Can. Geotech. J. 24, 565-580.

Parlange, J.-Y., Stagnitti, F., Heilig, A., Szilagyi, J., Parlange, M.B., Steenhuis, T.S., Hogarth, W.L., Barry, D.A., Li, L., 2001. Sudden drawdown and drainage of a horizontal aquifer. Water Resour. Res. 37, 2097-2101.

Szilagyi, J., Parlange, M.B., Albertson, J.D., 1998. Recession flow analysis for aquifer parameter determination. Water Resour. Res. 34, 1851-1857.

Van de Giesen, N.C., Parlange, J.-Y., Steenhuis, T.S., 1994 Transient flow to open drains: Comparison of linearized solutions with and without the Dupuit assumption. Water Resour. Res. 30, 3033-3039.

Whitham, G.B., 1974. Linear and Nonlinear Waves, Wiley, New York. 